\title{
MODELLING PARKING BEHAVIOUR CONSIDERING HETEROGENEITY
}

\author{
Gonzalo Antolín \\ Researcher, University de Cantabria, Spain \\ Ángel Ibeas \\ Professor, University de Cantabria, Spain \\ Borja Alonso \\ Associate Professor, Universidad de Cantabria, Spain \\ Luigi dell Olio \\ Professor, University de Cantabria, Spain
}

\begin{abstract}
Most of motorized trips in cities of middle and small size are made in public transport and mainly in private vehicle, this has caused a saturation in parking systems of the cities, causing important problems to society, one of the most important problems is high occupancy of public space by parking systems. Thus, is required the estimation of models that reproduce users' behaviour when they are choosing for parking in cities, to carry out transport policies to improve transport efficiency and parking systems in the cities.
\end{abstract}

The aim of this paper is the specification and estimation of models that simulate users' behaviour when they are choosing among alternatives of parking that there are in the city: free on street parking, paid on street parking, paid on underground parking and Park and Ride (now there isn't). For this purpose, is proposed a multinomial logit model that consider systematic and random variations in tastes. Data of users' behaviour from the different alternatives of parking have been obtained with a stated preference surveys campaign which have been done in May 2015 in the principal parking zones of the city of Santander.

In this paper, we provide a number of improvements to previously developed methodologies because of we consider much more realism to create the scenarios stated preference survey, obtaining better adjustments.

\section{INTRODUCTION AND OBJECTIVES.}

Over recent years, both in developed and developing countries, the problems associated with means of transport have worsened due to phenomena like congestion, longer journey times and increasing levels of polution (Ortuzar and Willumsen, 2008). 
Decision makers have tried to improve this situation in cities by introducing different management policies. Typical parking policies currently used are those which relate to the management of parking spaces for private cars (Marsden, 2006). Parking policies can affect different aspects of urban transport systems such as the efficiency and service standards of public transport and urban roads and pollution levels. Studies like Shoup, (2006) indicate that around a third of the traffic circulating in cities is actually looking for somewhere to park.

The correct design of parking policies aimed at reducing urban congestion requires in-depth knowledge about driver behaviour when choosing where to park.

The main aim of this research is to characterise and simulate driver behaviour when they decide on the type of parking they are going to choose. This research is particularly interested in characterising the behaviour of the different groups of urban drivers so they have been split into three groups depending on the parking choice they make when asked in the Stated Preferences (SP) survey.

The driver behaviour data was obtained from a SP survey asked in the city of Santander in May 2015 in different parts of the city to resident and non resident drivers. This data has been used to estimate logit models with random parameters considering systematic and random heterogeneities in user taste, run between the users of each parking choice and including panel effects in the responses.

The article is structured in the following way: section 2 provides a bibliographic review of the most relevant material published relating to the subject being investigated. This is followed by a description of the methodology used for the SP survey and the estimation of the models. Section 4 describes the specification and estimation of the discrete choice models along with a discussion of the main results. Finally, section 5 presents the most relevant conclusions drawn from this work of research.

\section{LITERATURE REVIEW.}

The saturation of available urban parking has been one of the principal causes of deteriorating traffic systems in large cities mainly due to increased cruising time for parking. Authors like Shoup, (2006), found that at certain times of day $30 \%$ of the traffic moving in city centres was actually looking for somewhere to park. This is a major problem contributing to increased congestion, pollution and journey times, as shown by authors such as (Box, 2004) or (Ukpong et al, 2006).

Various authors have studied how to address parking problems by assessing how drivers react to the introduction of new parking policies. Ahmadi et al. (2013), studied the willingness of drivers travelling to the CBD of Mashhad (Malaysia) to switch from their 
private vehicle to public transport depending on the parking tariff. Washbrook et al. (2006) evaluated driver willingness to car share or use public transport if there was a BUS-VAO lane and tariffs for parking; Kuppam et al. (1998) studies an area of Washington D.C. to see how users would react to the introduction of parking tariffs and the possibility of companies providing their employees with passes for public transport.

Examples of models aimed at analysing user behaviour when parking have been proposed by (Shoup, 2006), (Hensher and King, 2001), (Sattayhatewa and Smith, 2003) and (Guo et al, 2013b) who designed models to predict the decision of where the user was going to park, considering the parking fee, distance from final destination and the availability of public transport, etc. All of these are based on using discrete choice models centred on experimental designs of stated preferences surveys (SP). However, these models do not consider the availability of parking within the context of choice.

Hess and Polak (2004) developed research on driver behaviour when choosing where to park in various United Kingdom cities using mixed logit models. They found that cruising time for parking and time to final destination showed significant variations in taste; the differences in these parameters were mainly due to the reason for the journey taking place. Another example from the same authors, Hess and Polak (2009) describes the development of a model which included illegal parking as one of the alternatives, to show how this activity changed when the characteristics of other types of parking were changed.

We also found how Ibeas et al. (2014), developed mixed logit models to analyse the behaviour of drivers reacting to the construction of a new paid underground car park, concluding that the tariff and the time taken to find the car park as well as the time to their final destination were highly significant for the drivers. They also found that the perceived time to finding the car park was less important than the time they took to reach their final destination.

In further research using SP survey data, dell'Olio et al. (2009), the authors developed a methodology following which the survey was based on the use of random intervals for generating the variation levels for the variables used in the survey.

\section{METHODOLOGY.}

A SP survey was asked at different locations in the city of Santander (Figure 1). This survey not only allowed us to analyse user behaviour when choosing where to park, it also provided the data required to establish parking policies in urban areas. 


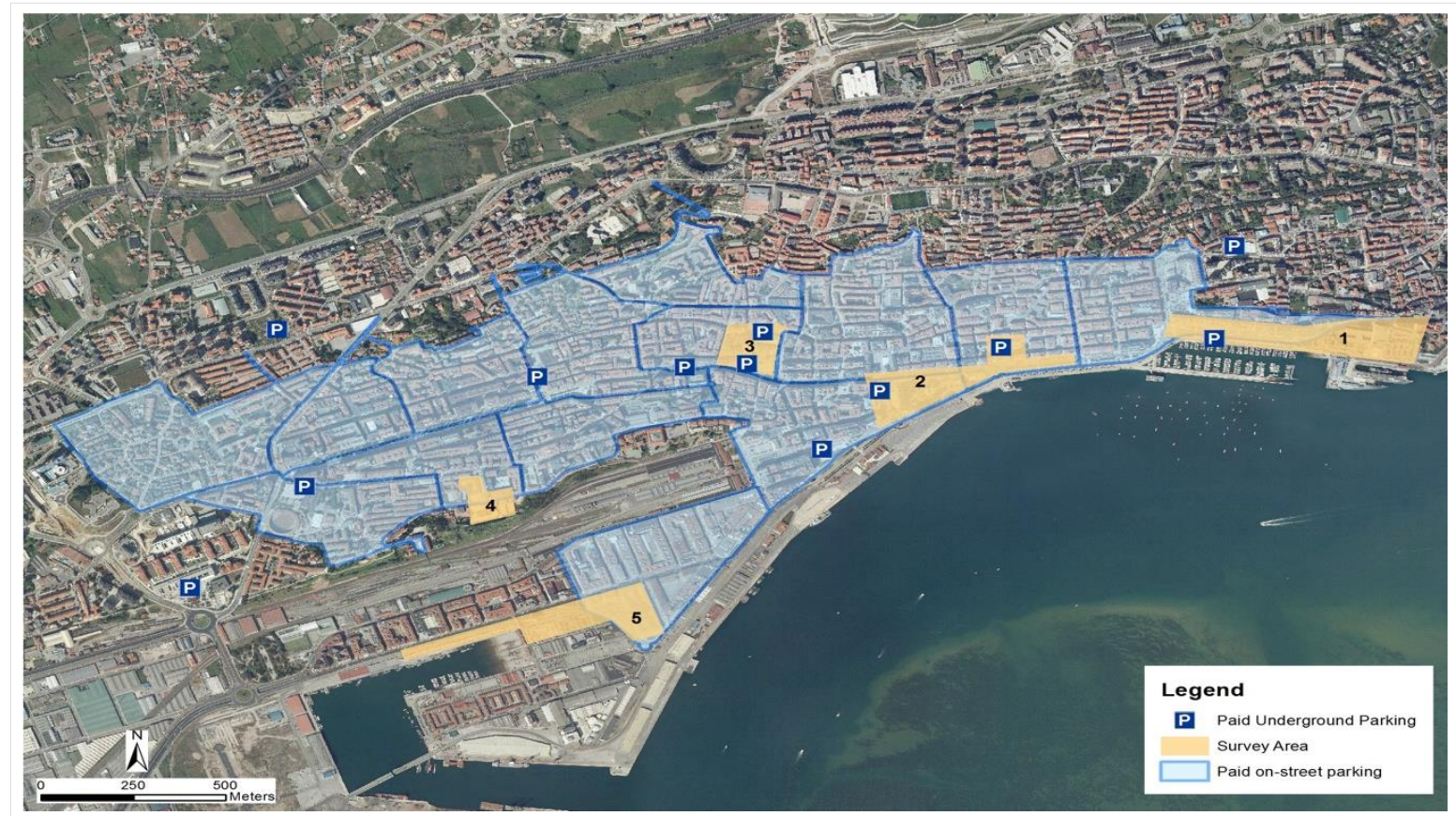

Figure 1. Locations where the SP survey was asked.

The designed SP survey consisted of 12 choice scenarios, divided into two blocks of 6 scenarios to facilitate comprehension. The survey was based on the following parking alternatives:

- $\quad$ Free On Street Parking (FOSP).

- Paid On Street Parking (POSP).

- Paid Underground Parking (PUP).

- Park \& Ride (P\&R).

The last alternative, Park \& Ride, does not currently exist in Santander, however, it was included because it will probably be introduced in the near future. The $P \& R$ alternative was included in the survey as being only available to the non residents whose journey began outside the city.

In the design of the experiment, for the generation of the scenarios to be shown during the SP survey, each driver was only shown scenarios with the choice alternatives available in the zone where they were stopped (Figure 1). For this reason the city was divided into 5 zones in which drivers had different parking alternatives available to them.

The SP survey has been designed using the following choice variables:

- Tariff (TAR): the amount paid for parking, present in the paid on street parking, paid underground parking and Park and Ride choices.

- Time to destination (TD): the time spent going from the parking point to the real destination of the drivers. 
- Parking search time (PST): the time taken to find somewhere to park once they have arrived in the area they want to park in.

- Maximum allowed parking time (MAPT): the maximum time that the driver is able to leave their car in a space, present in the paid on street parking and the Park and Ride choices.

- Suitability of the arrival time (EA, LA): this variable was introduced into the experiment to represent the cases of arriving early to their destination (EA) or arriving late (LA).

- Available information about the Park and Ride alternative (INFO): variable representing the available information about the characteristics of the Park and Ride location.

Table 1 below shows how each of the variables used in the SP survey corresponds with each of the possible alternatives.

\begin{tabular}{ccccc}
\hline \multirow{2}{*}{ Variables } & \multicolumn{4}{c}{ Alternatives where they appear } \\
\cline { 2 - 5 } & FOSP & POSP & PUP & P\&R \\
\hline TAR & & X & X & X \\
TD & X & X & X & X \\
PST & & X & & X \\
MAPT & & X & X & X \\
EA,LA & & X & X & X
\end{tabular}

Table 1. Correspondence between variables used and parking alternatives

As can be seen in the table, all the variables have not been assigned to all the parking alternatives. In the alternative PUP was not considered the variable of TBU, because the focus groups found that the drivers practically never considered it as a possibility. In the case of TMAX, only in the alternatives POSP and P\&R were considered because the other two alternatives did not consider constraints on maximum parking time.

The scenarios used in the survey were designed using the D-error (Rose and Bliemer, 2009) technique, providing the 12 optimal scenarios for the experiment. The different alternatives to be shown to the drivers were generated in the survey adapting the values to the journey the drivers had made at the moment of the survey. Depending on the zonal location of the survey, the drivers had different parking alternatives available to them; the fictitious parking alternatives shown to each driver were created from the variation of the characteristics the journey they made so the alternatives shown varied as a function of the tariff, search time, parking time and place of residence.

The choice of the variables used for designing the SP survey was made considering the research group's previous experience (dell'Olio et al., 2009), through the use of focus groups (Ibeas et al., 2011) and through international bibliographic review. In the focus groups, the participants were surveyed about the existing parking problems in the city and how they would react to the introduction of new parking policies. They were also asked about which type of parking they used and under what circumstances would they change to using a 
different alternative available in their zone.

The focus groups revealed that the participants who resided in the central areas of the city, where parking policies were already in place, were more prepared to pay for parking and on the contrary, those who lived in areas still free from established policies were prepared to invest more time to cruising to find free parking further away from their final destination.

The variables provided by the focus groups and the literature were used in a pilot survey on a small sample of the population. The objectives of this pilot survey are explained below:

- Check that the survey had been designed correctly for the objectives of the research.

- The final survey design, obtain the new prior values for the parameters used.

The sample size, 224 interviews, was obtained after the final survey design, representing the minimum number of observations necessary for each of the parameters. The interviewees were stopped in the street or at the exit of one of the car parks (in the case of the underground car parks) in each of the zones where the survey was asked. The moment chosen to ask the users was when they had just finished parking. To solve the problem of surveying a random sample of drivers in each of the zones, each interviewer was assigned a stretch of street in the zone and told to interview every third driver that parked.

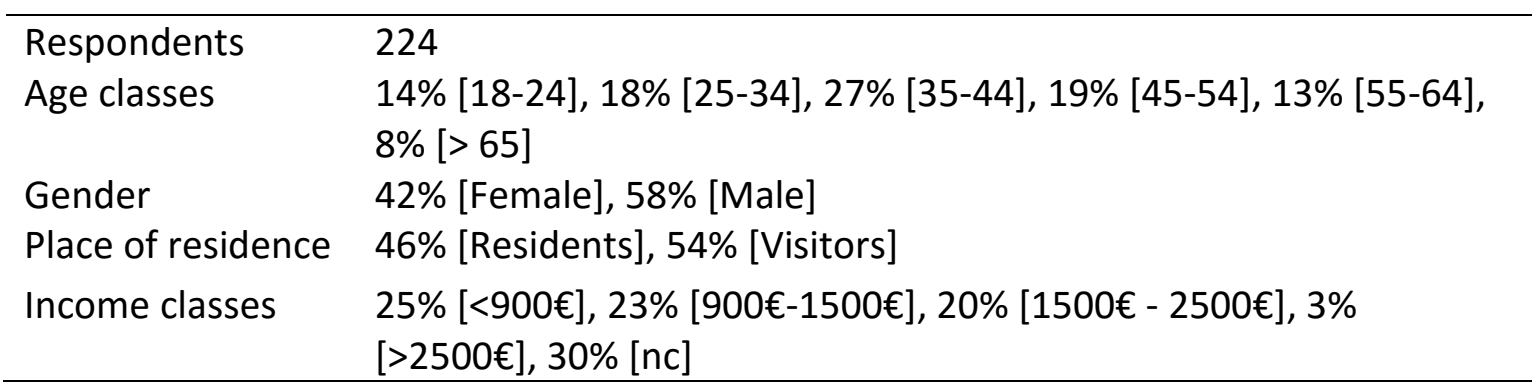

Table 2. Socio-demographic characteristics of the interviewees.

Table 2 shows the composition of the sample of drivers surveyed and it can be seen that $58 \%$ are men and that 54\% were not residents of Santander. Furthermore, 27\% of those surveyed were in the age range of $35-44$, which was the largest group.

\section{ESTIMATED MODELS.}

The three estimated models based on the data from the SP experiment are presented in this section. Different mixed logit models with panel effects have been estimated for each of the surveyed user groups. Thereby separately addressing the users of each type of available parking in the city. 
The following variables were found to be significant in the estimated models:

- $\mathrm{C}_{\mathrm{FOSP}}$ : Specific constant for the alternative FOSP.

- $\mathrm{C}_{\mathrm{POSP}}$ : Specific constant for the alternative POSP.

- $\mathrm{C}_{\mathrm{PUP}}$ : Specific constant for the alternative PUP.

- $\mathrm{C}_{\mathrm{P} \& \mathrm{R}}$ : Specific constant for the alternative P\&R.

- $\beta_{\mathrm{TAR}}$ : Parking tariff, specific parameter for each alternative.

- $\beta_{\mathrm{PST}}$ : Cruising time for parking, specific parameter for the alternatives POSP and PUP.

- $\beta_{\mathrm{TD}}$ : Access time to final destination from parking place, specific parameter for each alternative.

- $\beta_{\text {MAPT }}$ : Maximum permitted parking time, specific parameter for the alternatives POSP and P\&R.

- $\quad \beta_{\mathrm{TP}}$ : Dummy variable relative to time parked (worth 1 if 2 hours or less and 0 in other cases). Specific parameter for the alternative POSP.

- $\beta_{\mathrm{TR}}$ : Annual subscription card for parking in the area of POSP where his home is located.

- $\beta_{\text {INFO }}$ : Dummy variable relative to the presence of information about available parking spaces and the waiting time for public transport. Specific parameter relative to the alternative $\mathrm{P} \& \mathrm{R}$.

- $\beta_{\mathrm{LA}}$ : Variable indicative of the scenario representing the case of arriving later than the desired time.

- $\beta_{\mathrm{EA}}$ : Variable indicative of the scenario representing the case of arriving earlier than the desired time.

- $\quad$ TAR - HOME $E_{\mathrm{POSP}}$ : Interaction of the socio-economic variable reason for journey return home and the tariff associated to the parking alternative POSP.

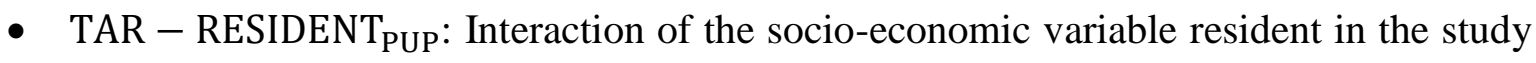
area and the tariff associated with the parking alternative PUP.

The mixed logit model used here is able to incorporate the variations in taste for the variables used in the utility functions of each parking alternative, for which the model can use random parameters for the variables. This model has a hedonic formulation with random parameters representing the variations in the tastes of individuals. The formulation of the model is as follows (Ortúzar and Willumsen, 2008):

$$
P_{q}\left(\tau^{*}\right)=\int S_{q}(\theta) f\left(\theta \mid \tau^{*}\right) d \theta
$$

where $S_{q}(\theta)$ is the probability of the MNL model, $f\left(\theta \mid \tau^{*}\right)$ is the function of density by which the population's tastes vary and $\tau^{*}$ represents the mean and the standard deviation of the population's tastes. 
Table 3 shows the models estimated for each of the groups of users which have been divided according to the type of parking used. Firstly, the FOSP user choice model is shown followed by the models for the POSP and PUP users. Each group of users of each parking alternative could choose from all the available kinds of parking corresponding to the zone they were in. Furthermore, the P\&R alternative was made available to the non residents who started their journey from outside the study area.

The models show that all the variables carry the expected sign, where the price, cruising time for parking and time to final destination are all negative and the rest of the variables have a positive sign.

In these models, evidence was found of the presence of random choice in the tariff variable, associated with the alternatives FOSP and PUP. In both cases the Normal distribution was found to best represent them.

On the other hand, the estimation of the models also took into account the interaction of various attributes with socio-economic variables (SE) such as the reason for the journey made and being a resident or not in the study area (Santander). We found that the only attribute that had interactions of this type was the tariff for paid on street parking, POSP, and underground parking. These interactions were found in the case of the specific models for the users of FOSP and PUP. Furthermore, because each driver was presented with six different scenarios panel effects were considered in the replies of each individual.

\begin{tabular}{|c|c|c|c|c|c|c|}
\hline \multirow[t]{3}{*}{ Variable } & \multicolumn{2}{|c|}{ Users of FOSP } & \multicolumn{2}{|c|}{ Users of POSP } & \multicolumn{2}{|c|}{ Users of PUP } \\
\hline & Coefficient & T- stat & Coefficient & $\begin{array}{c}\mathrm{T}- \\
\text { stat }\end{array}$ & Coefficient & T- stat \\
\hline & \multicolumn{6}{|c|}{ Random parameters in utility functions } \\
\hline$\beta_{\mathrm{TAR}(\mathrm{POSP})}$ & $-0,663$ & $-4,51$ & - & - & -1.353 & $-3,15$ \\
\hline \multirow{2}{*}{$\beta_{\mathrm{TAR}(\mathrm{PUP})}$} & $-0,677$ & $-2,56$ & $-0,603$ & $-1,71$ & $-0,226$ & $-0,74$ \\
\hline & \multicolumn{6}{|c|}{ Non-random parameters in utility functions } \\
\hline $\mathrm{C}_{\mathrm{FOSP}}$ & 1,197 & 3.03 & - & - & - & - \\
\hline $\mathrm{C}_{\mathrm{POSP}}$ & $-0,898$ & $-1,93$ & $-1,402$ & $-3,65$ & 1,937 & 2,06 \\
\hline $\mathrm{C}_{\mathrm{PUP}}$ & - & - & $-0,477$ & - & 1,572 & 1,75 \\
\hline $\mathrm{C}_{\mathrm{P} \& \mathrm{R}}$ & - & - & $-1,485$ & $-3,13$ & - & - \\
\hline$\beta_{\mathrm{TAR}(\mathrm{P} \& \mathrm{R})}$ & $-0,414$ & $-2,44$ & - & - & $-0,848$ & $-2,21$ \\
\hline$\beta_{\text {PST(FOSP) }}$ & $-0,015$ & $-1,87$ & $-0,092$ & $-7,67$ & $-0,039$ & $-2,43$ \\
\hline$\beta_{\text {PST (POSP) }}$ & $-0,034$ & $-2,03$ & $-0,124$ & $-5,61$ & $-0,104$ & $-4,4$ \\
\hline$\beta_{\mathrm{TD}(\mathrm{FOSP})}$ & $-0,071$ & $-3,73$ & - & - & - & - \\
\hline$\beta_{\mathrm{TD}(\mathrm{POSP})}$ & - & - & - & - & $-0,142$ & $-3,44$ \\
\hline$\beta_{\mathrm{TD}(\mathrm{PUP})}$ & $-0,155$ & $-1,98$ & $-0,227$ & $-2,73$ & $-0,256$ & $-4,1$ \\
\hline$\beta_{\mathrm{TD}(\mathrm{P} \& \mathrm{R})}$ & - & - & $-0,79$ & $-4,15$ & $-0,087$ & $-1,54$ \\
\hline$\beta_{\text {MAPT(POSP) }}$ & 0,203 & 4,3 & - & - & - & - \\
\hline$\beta_{\text {MAPT(P\&R) }}$ & 0,025 & 1,51 & - & - & - & - \\
\hline
\end{tabular}




\begin{tabular}{|c|c|c|c|c|c|c|}
\hline$\beta_{\mathrm{TP}(\mathrm{POSP})}$ & - & - & 0,745 & 2,36 & - & - \\
\hline$\beta_{\mathrm{TR}}$ & - & - & 0,533 & 1,89 & - & - \\
\hline$\beta_{\text {INFO }}$ & - & - & 1,013 & 1,98 & - & - \\
\hline$\beta_{\mathrm{LA}}$ & 0,069 & 3,11 & 0,072 & 3,1 & 0,05 & 2,33 \\
\hline$\beta_{\mathrm{EA}}$ & 0,058 & 2,22 & - & - & - & - \\
\hline & \multicolumn{6}{|c|}{ Interaction terms of random parameters with $\mathrm{SE}$ variables } \\
\hline TAR - HOME $E_{\text {POSP }}$ & $-0,808$ & $-1,95$ & - & - & $-1,19$ & $-1,52$ \\
\hline \multirow{2}{*}{ TAR - RESIDENT ${ }_{\text {PUP }}$} & $-1,855$ & $-1,63$ & - & - & $-1,348$ & $-3,21$ \\
\hline & \multicolumn{6}{|c|}{ Standard deviations of parameter distributions } \\
\hline Sigma TAR(POSP) (N) & 0,535 & 4,21 & - & - & 1,194 & 3,1 \\
\hline Sigma TAR(PUP) (N) & 1,994 & 2,33 & 0,104 & 0,21 & 1,233 & 5,36 \\
\hline Log likelihood & \multicolumn{2}{|c|}{-483.116} & \multicolumn{2}{|c|}{-271.870} & \multicolumn{2}{|c|}{-272.302} \\
\hline $\begin{array}{l}\text { Log likelihood } \\
\text { (Constants only) }\end{array}$ & \multicolumn{2}{|c|}{-556.895} & \multicolumn{2}{|c|}{-343.828} & \multicolumn{2}{|c|}{-360.923} \\
\hline
\end{tabular}

Table 3. Coefficients and t-test for the estimated ML models.

\section{RESULTS OBTAINED FOR PARKING CHOICE BEHAVIOUR.}

The results from the survey and the estimated models presented in the previous section have provided an important number of findings about people's behaviour when looking for somewhere to park. These findings are discussed below.

\subsection{Users of free on-street parking.}

In the specific case of users of on street parking, initially it was found that the only variable having a random distribution was the tariff, in the cases of both POSP and PUP. These findings reveal that the users of FOSP have a heterogeneous perception of the importance of the tariffs for POSP and PUP; in other words, there is an important variability in the weight that each individual places on these attributes.

Studying the weights of the parameters shows how the parameters with the highest weight are those related to the parking tariffs for POSP, PUP and P\&R. These groups of random variables also present interactions with SE variables (if they are residents in the study area and if the destination is their home), the interaction of the POSP tariff with the indicative variable of destination home suggests the existence of little willingness on the part of the users of free street parking to have to pay to park in the street when they are returning home. On the other hand, the interaction of the PUP tariff with the indicative variable of residence in the study area indicates that the users of this type of parking who live in the city are less willing to park in paid underground car parks.

The parameter relative to cruising time for FOSP parking has little significance and a lower coefficient than that of cruising time for POSP, suggesting that the users of this parking alternative value cruising time less in POSP areas than FOSP areas. 
In this case the parameter $\beta_{\mathrm{MAPT}(\mathrm{POSP})}$ associated with the maximum permitted parking time variable was positive and significant, indicating that these users would be more willing to park in POSP areas should the permitted time increase.

\subsection{Users of paid on street parking.}

As in the previous case, the model referring to the users of POSP found evidence of random distribution in the tariff, but in this case only in the parameter associated to the PUP tariff. Here, the tariff parameter for POSP had little significance and for that reason it was not included in the model.

It was then observed that the variables with the parameters of greatest weight were TP(POSP) and INFO. The variable TP(POSP), as mentioned earlier, indicates that the length of stay in the POSP area is less than two hours, which suggests that this is an attractive choice for the users of POSP if they are going to stay for less than two hours, even if the maximum allowed time is longer than this figure. The parameter associated to the INFO variable addressing the availability of information about free parking spaces in the area for $P \& R$ is also significant with a high coefficient, which suggests that the users of POSP who are not residents in the study area have a greater willingness to change their parking choice and use the $P \& R$ service if the information is made available.

In the case of the POSP an analysis of the TR variable showed that if they possess a permit for parking in the area where they live, it shown that when they travel to another part of the city where their permit is not valid they are more likely to choose the POSP alternative.

\subsection{Users of underground car parks.}

As in the previous cases, the PUP user model has been analysed to study the behaviour of this group of users in the process of making their parking choice. Firstly, it was found that the tariff variable had a random distribution which was also present in the parameters associated to the POSP and PUP parking alternatives, showing, as in the previous cases the presence of heterogeneity in the perception of this variable.

Secondly, the parameters with greatest weight are those which relate to the alternative parking tariffs and the interactions of the tariffs with the SE variables (if the driver is resident in the study area and their destination is their home). In this case the same interaction has been found as with the FOSP users.

Finally, for these users it was found that the parameters with the greatest weight after those associated with the tariff are those associated with access time to final destination, indicating that for the PUP users the access time to final destination (TD) is if great importance when choosing where to park. It can also be seen that the parameters associated to the TD variable 
are higher than those associated to the cruising time for parking variable (PST), suggesting that for these users the time to get to their destination is more important than the time taken to find the car park.

\section{CONCLUSIONS}

The ability to predict the decisions of drivers when choosing where to park is essential for the development of policies relating to parking. As has been highlighted in the previous sections, traffic related to cruising for parking has an important bearing on general traffic flows and congestion in urban areas. Therefore, the overall modelling of urban traffic also requires the modelling of traffic related to parking.

This article presents the results of a SP survey asked to drivers in the city of Santander. This research has centred on understanding the choice of where to park and the requirements of different groups of users in the city when making that choice. The results show the importance of the parking tariff for the different groups of users analysed, as well as other conclusions that have been drawn from the application of the methodology, developed for this research, in the city of Santander, where the imposition of new parking policies are required.

The developed models show how the perception of different groups of users varies with respect to cruising time for parking. The users of POSP and PUP have a much lower perception of cruising time than those of FOSP, who are much more willing to spend more time looking for somewhere to park.

Analysing variables EA and LA related to with the possibility of arrive to the final destination early or late, relevant results are seen. The users of FOSP if they arrive early, they would willingness to change to the alternative $P \& R$, in the case of arrive late, they would willingness to pay for parking and use alternatives POSP and PUP. For users of POSP has been obtained that if they arrive late, they would willingness to change to the alternative of PUP. Finally, users of PUP in the case of arrive late would give more useful to its alternative parking, that is, PUP.

Other important aspects are also worth mentioning:

- The non resident parking users are more willing to pay for parking than are the residents in the study area.

- All the analysed groups of users have a worse perception of access time to final destination than they do of cruising time for parking.

- The users of FOSP are more willing to change to POSP or P\&R if the maximum allowed time for parking there is increased. 
Generally, the characterisation developed for each of the groups of parking users leads to various conclusions to assist in the development of future parking policies:

- If the city receives a great number of non resident drivers, such as tourists or workers making occasional journeys, the tariff could be higher compared to cities with fewer non resident journeys

- If it is desirable that the users of FOSP change their parking choice to POSP or P\&R, for example, the POSP zones need to be enlarged, and another possible policy would be to extend the maximum allowed staying time without having to move the car.

- In the case of installing a P\&R system, the developed model has shown that for the current users of POSP and PUP to switch over to using the new system it would have to have a very short access time among other measures.

\section{ACKNOWLEDGEMENTS}

This study and the development of future research are possible thanks to financing from the Spanish Ministerio de Economía y Competitividad from the project referenced TRA201348116-R.

\section{REFERENCES}

Ahmadi Azari, K., Arintono, S., Hamid, H., y Rahmat, R. A. O. K. (2013). Modelling demand under parking and cordon pricing policy. Transport Policy, 25, 1-9.

Box, P. C. (2004). Curb-parking problems: Overview. Journal of Transportation Engineering, 130 (1), 1-5.

Dell'Olio, L., Ibeas, A., y Moura, J. L. (2009). Paying for parking: improving statedpreference surveys. Proceedings of the ICE-Transport, 162(1), 39-45.

Guo, L., Huang, S., Zhuang, J., y Sadek, A. W. (2013). Modeling parking behavior under uncertainty: A static game theoretic versus a sequential neo-additive capacity modeling approach. Networks and Spatial Economics, 13(3), 327-350.

Hensher, D. A., \& King, J. (2001). Parking demand and responsiveness to supply, pricing and location in the Sydney central business district. Transportation Research Part A: Policy and Practice, 35(3), 177-196.

Hess, S., \& Polak, J. W. (2004, January). Mixed Logit estimation of parking type choice. In 83rd Annual Meeting of the Transportation Research Board, Washington, DC (pp. 561-582). Hess, S., \& Polak, J. W. (2009). Mixed Logit modelling of parking type choice behaviour. Transportation Statistics (77-102). JD Ross Publishing.

Ibeas, A., dell'Olio, L., y Barreda, R. (2011). Citizen Involvement in Promoting Sustainable Mobility. Journal of Transport Geography, 19 (4).

Ibeas, A., Dell'Olio, L., Bordagaray, M., \& Ortúzar, J. D. D. (2014). Modelling parking choices considering user heterogeneity. Transportation Research Part A: Policy and Practice, 70, 41-49.

Kuppam, A. R., Pendyala, R. M., y Gollakoti, M. A. V. (1998). Stated response analysis of the effectiveness of parking pricing strategies for transportation control. Transportation Research Record (1649), 39-46.

Marsden, G. (2006) The evidence base for parking policies--a review. Transport Policy 13, 
447-457.

Ortúzar, J de D y Willumsen, LG (2008) Modelos de Transporte. Traducción de A. Ibeas y L. Dell'Olio. PubliCan Ediciones de la Universidad de Cantabria.

Rose, J.M. y Bliemer, M.C.J., 2009. Constructing efficient stated choice experimental designs. Transp. Rev. 29, 587-617.

Sattayhatewa, P., y Smith jr., R. L. (2003). Development of parking choice models for special events. Transportation Research Record (1858), 31-38

Shoup, D. C. (2006). Cruising for parking. Transport Policy, 13(6), 479-486.

Thompson, R. G., \& Richardson, A. J. (1998). A parking search model. Transportation Research Part A: Policy and Practice, 32(3), 159-170.

Ukpong, I., Dissanayake, D., y Zhang, B. (2006). Development of a micro-simulation traffic model to investigate on-street parking and its impacts on sustainable environments: A case study in the city of Newcastle upon Tyne. 13th ITS World Congress, London, Toronto, Canada.

Washbrook, K., Haider, W., \& Jaccard, M. (2006). Estimating commuter mode choice: A discrete choice analysis of the impact of road pricing and parking charges. Transportation, 33(6), 621-639. 